\title{
BACTERIAS MARINAS CON CAPACIDAD ANTIMICROBIANA AISLADAS DE: MOLUSCOS BIVALVOS EN CULTIVOS
}

\section{MARINE BACTERIA WITH ANTIMICROBIALS CAPACITY ISOLATED FROM CULTURES, OF BIVALVE MOLLUSKS}

\author{
Fabiola Pellón Y. ${ }^{1,2}$, Rita Orozco M. ${ }^{2}$ y Jorge León Q. 1
}

\section{RESUMEN}

Los microorganismos han sido siempre objeto de estudios como productores de sustancias antibacterianas; sin embargo, también son consideradas productores de sustancias antifúngicas, antivirales, antiparasitarias, citotoxicas e inhibitorias de otras formas de crecimiento celular.

Este trabajo describe el aislamiento, el potencial inhibitorio y la caracterización fenotipica de cepas bacterianas nativas asociadas a los moluscos bivalvos Argopecten purpuratus "concha de abanico" y Crassostrea gigas "ostra" en sistemas de cultivo.

De un total de 345 cepas de hacterias colectadas se recuperaron 20 cepas marinas con capacidad inhibitoria de amplio espectro de bacterias patogenas de peces, moluscos y crustáceos; y los más sensibles fueron los patogenos Aeromonas sobria P-281. Aeromonas hydrophila ATCC 7966, Vibrio vuinificus ATCC 27562 y Vibrio parahaemolyticus ATCC 17803. La caracterización fenotipica de las cepas con capacidad inhibitoria permitió identificar los siguientes géneros: Vibrio (40\%), Aeromonas (15\%), Flavobacterium (10\%), Pseudomonas (5\%), Moraxella (5\%), Flexibacter (5\%). No fueron identificadas $20 \%$.

Los resultados sugieren que las bacterias aisladas podrian ser aprovechadas como agentes probióticos en el control biológico de patógenos de organismos marinos de interés en maricultura.

Palabras clave: Bacterias marinas, antibiosis, probióticos, maricultura, Argopecten purpuratus, Crassostrea gigas.

\section{ABSTRACT}

Microorganisms have commonly been studied as producers of antibacterial substances; yet they are also considered producers of antifungic, antiviral, antiparasitic, citotoxics and inhibitory of other forms of cellular growth substances.

This paper describes the isolation, inhibitory potential and phenotipic characterization of native bacterial strains associated to bivalve moliusks such as Argopecten purpuratus "concha de abanico" and Crassostrea gigas "ostra" in cultivation systems.

From 345 marine strains collected, 20 strains were recovered that had the ability of inhibiting a wide spectrum of fish, mollusks and shellfish pathogenic bacteria; being the most sensitive pathogens Aeromonas sobria P-281. Aeromonas hydrophila ATCC 7966, Vibrio vilnificus ATCC 27562 and Vibrio parahaemolyticus ATCC 17803 . The phenotipic characterization of this strains with inhibitory capacity allowed the identification of the following genera: Vibrio (40\%), Aeromonas (15\%), Flavobacterium (10\%), Pseudomonas (5\%), Moraxella (5\%), Flexibacter (5\%). A $20 \%$ could not be identified.

The results suggest that the isolated bacteria could be used as probiotics agents for the biological control of pathogens from marine organisms of interest in mariculture.

Key words: marine bacteria, antibiosis, probiotics, Argopecten purpuratus, Crassostrea gigas.

'Lab. Microbiologia Ambiental y Biotecnologia, Facultad de Ciencias Biołogicas, Universidad Nacional Mayor de San Marcos, Lima - Perú.

"Lab Microbiologia, Instituto del Mar del Perú - IMARPE. 


\section{INTRODUCCIÓN}

Los microorganismos marinos, asi como álgunos invertebrados han sido considerados virtuales productores de metabolitos biológicamente activos. Numerosos trabajos han revelado la existencia de cepas de bacterias marinas que producen diversos metabolitos secundarios, entre ellas las sustancias antibacterianas (Gauthier y Flatau. 1976; Dopazo et al., 1988; Lemos et al., 1985b; Marty y Martin, 1992).

En ambientes marinos la búsqueda de bacterias nativas con capacidad inhibitoria se ha realizado a partir de diversas muestras (agua, sedimentos, plancton, vertebrados e invertebrados) (Toranzo et al., 1982; Lemos et. al., 1985b; Nair y Simidu, 1987; Dopazo et al., 1988). Las superficies y espacios internos de organismos marinos son considerados microhábitats donde se encuentran regularmente los microorganismos, que son considerados objeto de estudio para el aislamiento de diversas bacterias con potencial biológico (Bonar et al. 1986).

Los cultivos de bivalvos marinos, tales como Argopecten purpuralus "concha de abanico" y Crassostrea gigas "ostras", se ven obstaculizados por la elevada mortalidad larval que se atribuye a la presencia de bacterias patógenas marinas como Vibrio anguillarum y Vibrio alginolyticus (Navarro et al., 1991; Riquelme et al., 1995). Por otro lado, los antibióticos son usados por los acuicultores como una forma de prevenir el establecimiento de bacterias patógenas y en el tratamiento de especies afectadas (Jeanthon et al., 1988; Karunasagar et al., 1994). Sin embargo, el uso de estos antibióticos tiene también aplicabilidad limitada en esta actividad, debido a que los patógenos marinos al igual que otras bacterias desarrollan la capacidad de resistencia a dichos antibióticos (Riquelme el al., 1996) como consecuencia de la transferencia rápida de resistencia mediada por plásmidos (Westerdahl et al., 1991). Un método alternativo para controlar los diferentes problemas microbiológicos que se presentan en los sistemas de cultivos, podria ser la adición de cultivos puros de bacterias nativas productoras de sustancias inhibitorias de bacterias patógenas marinas (Riquelme et al., 1996: Douillet y Langdon, 1994; León, 1996).

El presente trabajo, describe el aislamiento, el potencial inhibitorio y caracterización fenolípica de la flora nativa bacteriana asociada a cultivos de Argopecten purpuratus "concha de abanico" y Crassostrea gigas "ostra".

\section{MATERIALES $Y$ METODOS}

\section{Lugar de muestreo y recolección de muestras}

Para ef aislamiento y estudio de bacterias marinas con capacidad inhibitoria se colectaron 70 muestras de Argopecten purpuratus "concha de abanico" y 15 de Crassostreagigas "ostra" cultivadas en las zonas denominadas El Carbon (12.27'06"S y 76 47'07"W) y La Tiza (12.26.00"S y 76.46.30"W) en Pucusana y la Isla San Lorenzo (12005'30"S y $77^{\circ} 11^{\prime} 28^{\prime} \mathrm{W}$ ) en el Callao. Las muestras fueron recolectadas en forma aséptica y conservadas en hielo hasta su procesamiento en el laboratorio.

\section{Procesamiento de las muestras y aisla- miento de bacterias, marinas}

Las muestras se procesaron mediante la técnica descrita por León (1996). Se realizó la disección respectiva de los bivalvos bajo condiciones estériles y se prepararon diluciones al décimo a partir de un primer homogenizado de tejido blando $(25 \mathrm{~g}$ de tejido en $225 \mathrm{ml}$ de agua de mar fijtrada y esterilizada). Para el aislamiento de bacterias marinas las muestras. diluidas se homogenizaron en un "vortex mixer", y se diseminaron alicuotas $(0,1 \mathrm{mi})$ de cada dilución sobre la superficie de placas con Agar Marino Modificado (MA) (g/l: Bactopeptona 5,0; Extracto de levadura 2,0; Bacto- 


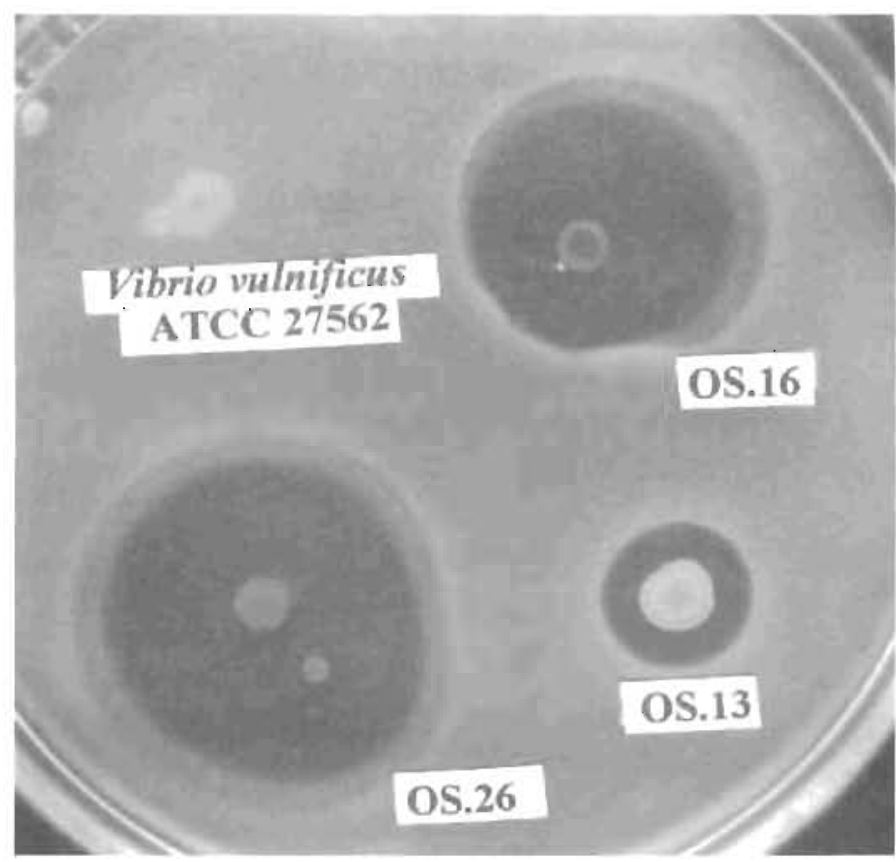

Figura 1. Inhibición de Vibrio vunificus ATCC 27562 por las cepas OS.16 y OS.26, (halos de inhibición de 25 y $30 \mathrm{~mm}$ de diámetro respectivamente) y la cepa OS.13 (halo de inhibición de $14 \mathrm{~mm}$ de diámetro).

agar 15,0 ; agua de mar añeja $750 \mathrm{ml}$ y agua destilada $250 \mathrm{ml}$. pH final: 7,6), Las placas fueron sembradas por duplicado e incubadas a $20^{\circ} \mathrm{C}$ durante 6 dias.

\section{Selección y conservación de bacterias inhibitorias.}

Para la selección de bacterias marinas productoras de sustancias inhibitorias se aplicó el método de "doble capa" șegún Dopazo et al. (1988) utilizando como cepa control a Staphylococcus cureus ATCC 6633. Las coIonias de bacterias marinas que presentaron halos de inhibición frente a la cepa control fueron consideradas inhibitorias y conservadas en el medio MA semisólido para cultivos de rutina en estudios posteriores.

\section{Pruebas de antibiosis frente a bacterias patógenas de peces y moluscos}

Para las pruebas de antibiosis frente a bacterias patógenas de peces y moluscos se utilizaron 9 cepas patógenas de colección (dona- das por la University of Maryland Biotechnology Institute, USA, y Universidad de Santiago de Compostela, España) (Tabla 1). El espectro de antibiosis de las cepas marinas aisladas fue evaluado por el método modificado de Westerdahl et al. (1991). Según este método las cepas en estudio se cultivaron para formar macrocolonias en el medio M.A y fueron incubadas a $20^{\circ} \mathrm{C}$ durante 5 días. Después de la incubación las placas con los cultivos fueron sometidos a vapores de cloroformo por 45 minutos e inmediatamente se agregó una segunda capa de agar semisólido previamente inoculado con la bacteria patógena en prueba. Los cultivos fueron incubados a $30^{\circ} \mathrm{C}$ durante $24-30$ horas. La presencia de un halo de inhibición definido alrededor de las macrocolonias fue considerada actividad antibacteriana.

\section{Caracterización fenotípica de bacterias inhibitorias}

Las cepas inhibitorias de bacterias patógenas de peces y moluscos previamente 


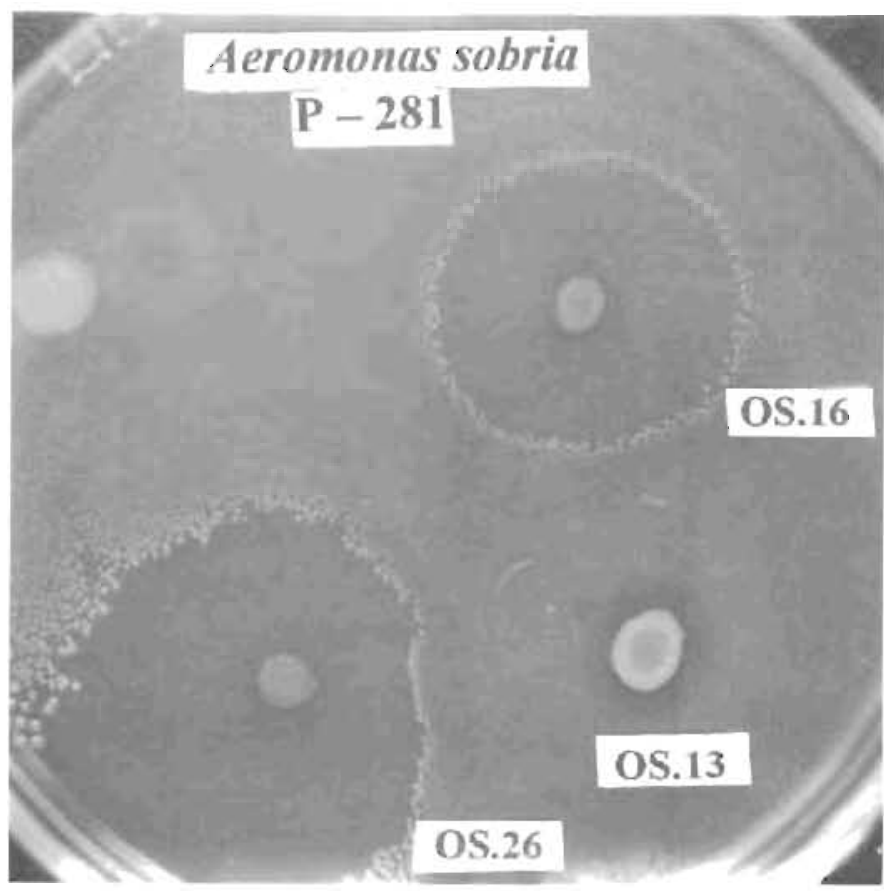

Figura 2. Actividad inhibitoria de las cepas OS.16, OS.26 y OS.13 sobre Aeromonas sobria P281. Obsérvese las diferencias en la capacidad inhibitoria de las cepas nativas frente al patógeno (halos de inhibicion de 31,36 y $11 \mathrm{~mm}$ de diametro respectivamente).

seleccionadas fueron sometidas a caracterización fenotipica. Estas cepas fueron evaluadas mediante pruebas morfológicas fisiológicas y bioquimicas siguiendo los procedimientos descritos por Baumam et al. (1972), Olivei (1982), Ortigosa et al (1994), Jensen y Fenical (1995). La caracterización fenotipica se realizó mediante las siguientes pruebas convencionales: morfología celular, motilidad, carácter Gram, formación de pigmentos, luminiscencia, citocromo-oxidasa, catalasa, metabolismo oxido-fermentativo (OF), reducción de nitrato, actividades enzimáticas extracelulares (hidrólisis de gelatina, caséna, almidón, DNA, celulosa, tween 80 , queratina y lecitina), requirimiento de agua de mar para el crecimicnto y otras pruebas complementarias. El medio base para todas las pruebas fue Caldo Marino (MB) o Agar Marino (MA). La temperatura de incubación fue de $23^{\circ} \mathrm{C}$ y la lectura final se realizó a los 4-5 dias, excepto para la producción de enzimas extracelulares, caso en que el tiempo de incubación se protongó hasta 10 días.

\section{Identificación de bacterias inhibitorias}

Para la identificación de bacterias inhibitorias a nivel de género se emplearon los esquemas taxonómicos para bacterias marinas de Oliver (1982), Sawabe et al. (1995) y Jensen y Fenical (1995). Adicionalmente se utilizó el sistema de identificación API $20 \mathrm{NE}$ (Sistema de Identificación de Bacterias Gram Negativas No Enterobacterias) para 5 cepas de bacterias aisladas que fueron seleccionadas por su mayor espectro de actividad inhibitoria de las bacterias patógenas en prueba.

\section{RESULTADOS}

\section{Aislamiento y selección de bacterias inhibitorias}

De un tolal de 85 bivalvos procesados se lograron obtener inicialmente 345 aislados de bacterias marinas, de las cuales 83 (100\%) mostraron capacidad inhibitoria de la cepa control Staphylococcus aureus $\mathrm{ATCC}$ 
Tabla 1. Cepas patogenas de peces y moluscos utilizadas en las pruebas de antagonismo.

\begin{tabular}{|c|c|c|}
\hline CEPAS & AISLAMIENTO & PROCEDENCIA \\
\hline Vibrio anguillamum NCMB $2133^{\text {(a) }}$ & Desconocido & Noruega \\
\hline Vibrio anguillarum ATCC 19264 (u) & Bacalao & Dinamarca \\
\hline Vibrio splendidus ATCC 33125 (b) & Salmónido & USA \\
\hline Vibrio culnificus AT (C 27562 (b) & Salr tunido & USA \\
\hline Vibrio parahaemolyticus ATCC $17803^{(\mathrm{h})}$ & Desconocido & USA \\
\hline Aeromonas sobria $\mathrm{P}-281$ & Trucha"arco iris" & España \\
\hline Acromonas hydrophila ATCC 7966 (1) & Trucha "arco iris" & España \\
\hline Psetutomonas aeruginosa AICC 15442 & Desconocido & USA \\
\hline Yersinia ruckeni $\mathrm{PP}^{\mathrm{P}}-31$ & Trucha "arco iris" & España \\
\hline Staphylococtus aureus ATCC 6633 * & - & Chile \\
\hline
\end{tabular}

(i) Cepas donadas por la Dra. Alicia E. Toranzo, Facultad de Cinncias Biológicas, Departantento de Microbiologia - Universidad de Sanliago de Compostela, España.

(1) Cepas donadas por la Dra. Rita Colwell, University of Maryland Biotechnology Institute, USA.

* Cepa utilizada como testigo en los ensayos de antagonismo.

6633 ; y de ellas 45 (54\%) cepas fueron aisladas de Crassosirea gigas "ostras" y 38 (46\%) de Argopercten purpuratur" "concha de abanico".

\section{Antibiosis frente a bacterias patógenas de peces y moluscos}

De la lotalidad decepas inhibitorias aisladas inicialmente, 20 fueron seleccionadas por mostrar amplia actividad de antibiosis frente a las cepas de colección de bacterias patógenas de peces y moluscos (halos de inhibición promedio de 20 num de diámctro). Del grupo de las cepas seleccionadas, 14 fueron aisladas de Argopecten purpuratus "concha de abanico" (cepas CA) y $6 \mathrm{de}$ Crassostrea gigas "ostras" (cepas OS). Los resultados de la actividad inhibitoria de las 20 cepas se observan en la tabla 2 . Entre las cepas de mayor actividad inhibitoria estuvieron las indicadas por las siglas OS.26, OS.16, OS.13, CA.19 y CA.21; siendo las cepas OS.16, OS.26 y OS.13 las que mostraron actividad de amplio espectro sobre la totalidad de los patógenos ensayados.

Asimismo, los patógenos más sensibles a la actividad inhibitoria de las cepas marinas fueron Aeromonas sobria P-281, Vibrio vulnificus ATCC 27562, $V$. parahaemolyticus ATCC 17803 y $A$. hydrophila ATCC 7966, seguidas por otros patógenos miembros del género Vibrio. Pseudomonas aeruginosa ATCC 15442 y Yersinia ruckeri PP-3 I considerados como patógenos de origen no necesariamente marinos mostraron menor sensibilidad.

Cahe resaltar la actividad inhibitoria mostrada por las cepas OS.26 y OS.16, las que además de su total antibiosis sobre los patógenos ensayados, presentaron halos de inhibición de hasta $35 \mathrm{~mm}$ de diámetro. Esta fuerte actividad mostrada frente a Vibrio vulnificus ATCC 27562 y Aeromonas sobria P-281 se observa en las tiguras 1 y 2 . La cepa OS.13 también mostró actividad antagónica sobre la totalidad de los patógenos; sin embargo, la magnitud de su inhibición fue menor en comparación con otras cepas.

\section{Caracterización fenotipica de bacterias inhibitorias}

Las bacterias inhibitorias estudiadas mostraron caracteristicas morfológicas y fisiológicas tipicas de bacterias marinas (Tabla 3). 


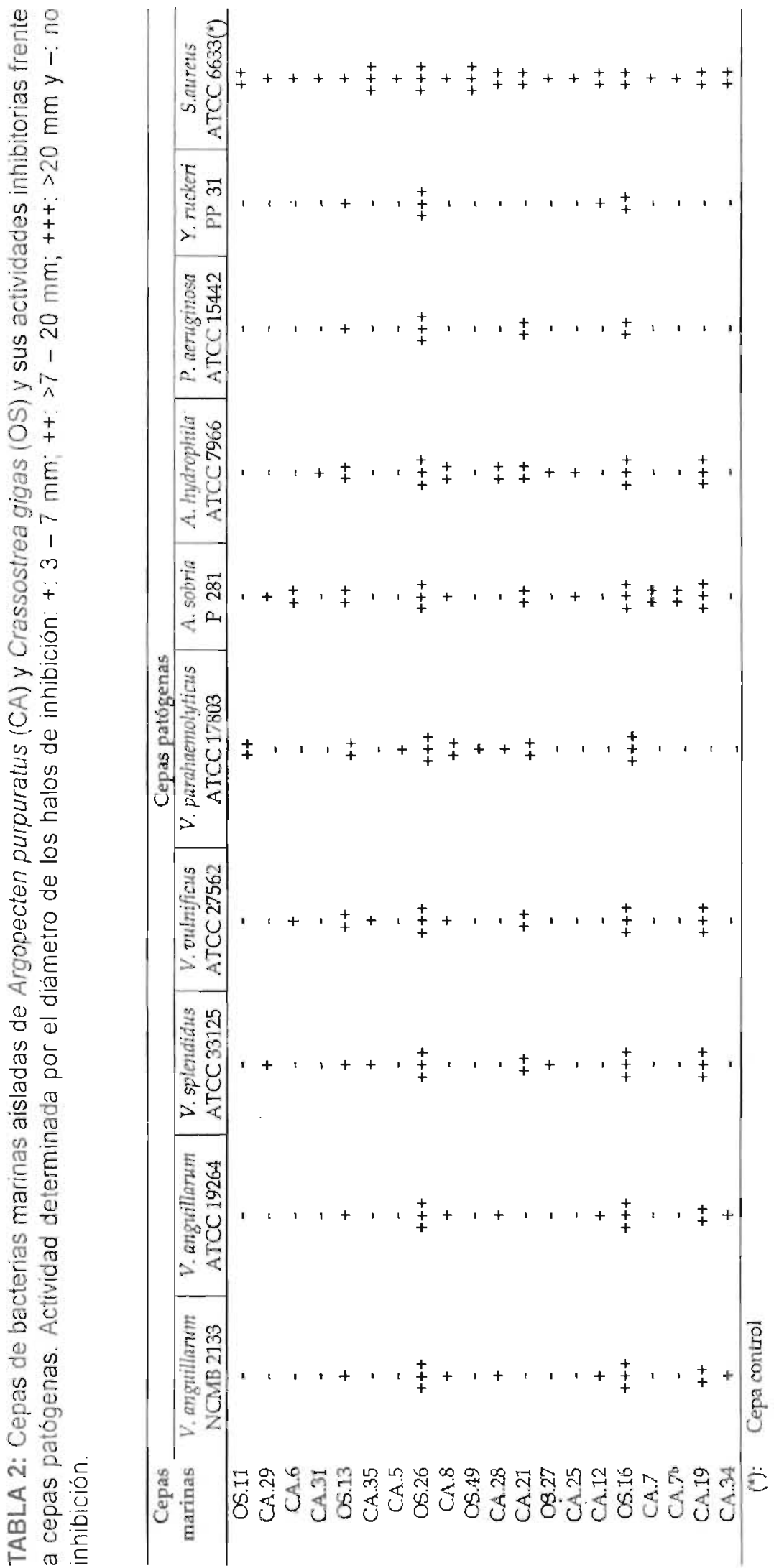




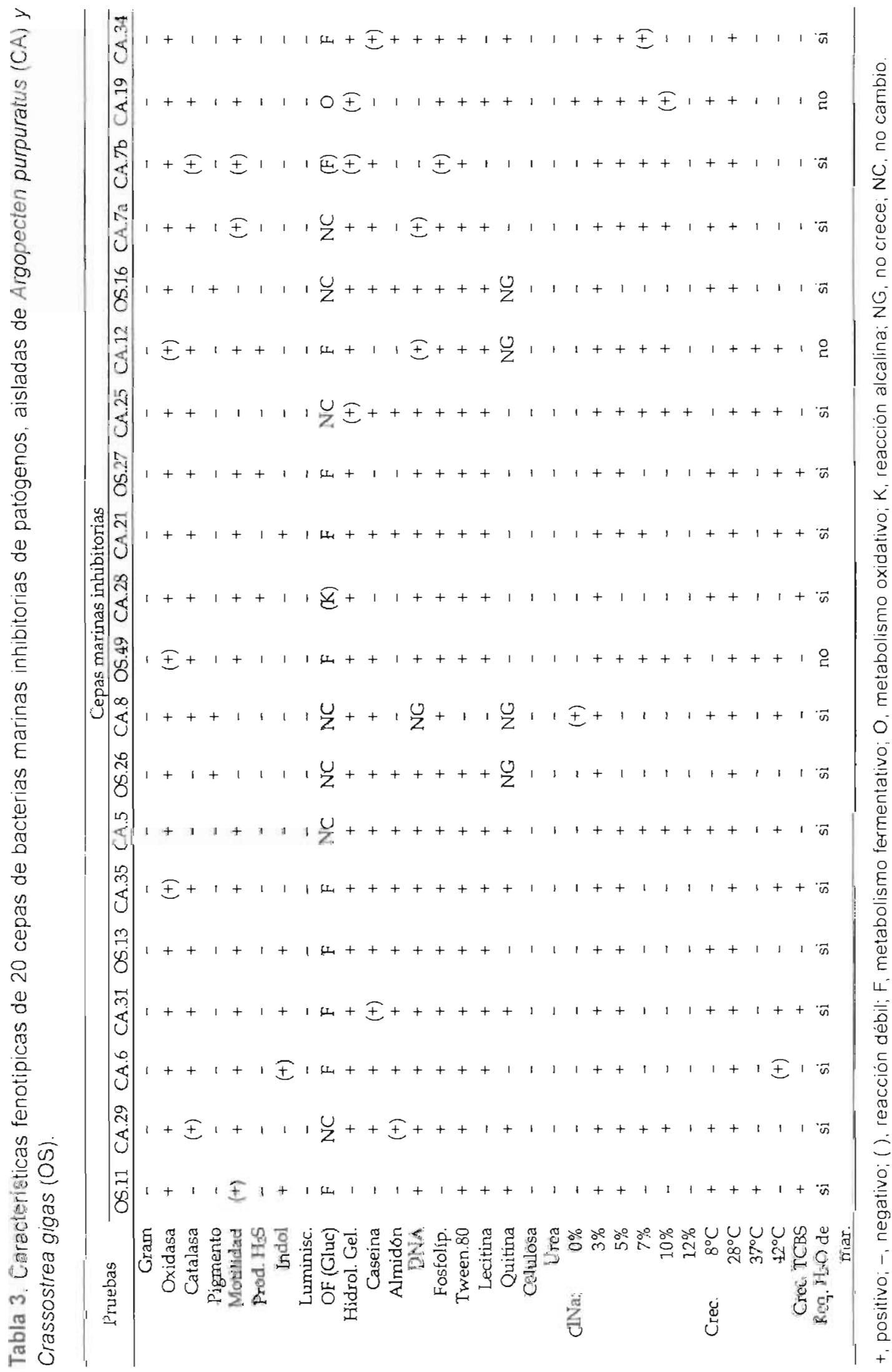


Tabla 4. Géneros identificados de bacterias marinas con actividad inhibitoria aisladas de $A$ purpuratus y $C$. gigas en cultivo.

\begin{tabular}{rlcc}
\hline GENERO & \multicolumn{1}{c}{ CEPAS } & N. ${ }^{\circ}$ de CEPAS & (\%) \\
\hline Vibrio & CA.6, CA.31, OS.13, CA.35, & 8 & 40 \\
& OS.49, CA.21, CA.12 y CA.34. & & \\
Aeromonas & OS.11, CA.28 y OS.27 & 3 & 15 \\
Flavobacterium & OS.16 y OS.26. & 2 & 10 \\
Pseudomonas & CA.19 & 1 & 5 \\
Moraxelia & CA.25 & 1 & 5 \\
Flexibacter & CA.8 & 1 & 5 \\
No identificados & CA.29, CA.5, CA.7a y CA.7b & 4 & 20 \\
TOTAL & 20 & 100 \\
\hline
\end{tabular}

La mayoría de las cepas presentaron la forma típica de bacilos cortos y excepcionalmente en filamentos finos, todas Gram neyativas con un marcado pleomorfismo. Asimismo, el 75\% de las cepas presentaron movilidad por flagelos. En cuanto al comportamiento cultural en medio sólido la mayoría presentaron características similares, tales como colonias circulares y pequeñas (2 a $4 \mathrm{~mm}$ de diámetro), superficie lisa, convexas, brillosas, borde entero y de consistencia cremosa. Las cepas OS. 26 y.OS. 16 presentaron características de cultivo similares, y ambas fueron colonias ligeramente elevadas, borde entero, superficie lisa, consistencia cremosa y pigmentación de color amarillo limón difusible en el medio. En cultivos prolongados las cepas OS.26 y OS. 16 tormaron a un color amarillo ocre y la cepa CA. 19 a verde fluorescente. En cl Caldo Marino, la mayoria de las cepas presentaron turbiedad homogénea con desarrollo lento, sedimento moderado y escasa formación de película en superficie. Todas las cepas fuercin positivas a la reacción de la oxidasa. Vinguna mostró luminiscencia.

En cuanto al metabolismo OF de la glucosa el comportamiento fue variable; sin embargo. sólo la cepa CA.19 mostró metabolismo oxidativo. Ninguna de las cepas produjo gas a partir de glueosa.

Con relación a la producción de enzimas extracelulares, la mayoría de cepas mostraron ser productores de algunas de estas enzimas tales como gelatinasa, tween esterasa, fosfolipasa, DNAsa, lecitinasa, caseinasa, amilasa y quitinasa. Ninguna cepa fue positiva en la producción de ureasa y celulasa. En la prueba de requerimiento de agua de mar, la mayoría de las cepas requirieron de agua de mar para crecer, a excepción de las cepas OS.49, CA. 12 y CA. 19.

\section{Identificación de las cepas inhibitorias}

Las 20 cepas inhibitorias seleccionadas y caracterizadas lenotípicamente fueron identificadas como miembros de los géneros Vibrio (40\%), Aeromonas (15\%), Flavobuclerium (10\%), Pseudomonas (5\%), Moraxella (5\%) y Flexibacter $(5 \%)$. Cuatro cepas no fueron identificadas (20\%) (Tabla 4 ).

Los resultados con el sistema de identificación API 20NE fueron similares a los obtenidos mediante pruebas hioquimicas convencionales.

\section{DISCUSIÓN}

Trabajos orientados a la búsqueda de bacterias nativas con capacidad inhibitoria describen a dichas cepas como epibiontes, epifitas o parte de la microflora nativa del tracto digestivo del hospedero (Lemos et al., 1985b; Bonar et al., 1986). En consecuencia, nuestros resultados ratifican que invertebrados marinos como Argopecien purpuralus y Crassostrea gigas son también hospederos de una variada flora microbiana y entre ellas 
aquellas que tienen actividad antibacteriana. Se afirma quic en la interacción invertebradosbacturias el rol que desempeñan los microorganismos está relacionado con activiJades como simbiosis, sinergismo, antagonismo u otra modalidad de interacción (Bonar et al. 1986: Nair y Simidu, 1987). En el caso particular del presente trabajo, la capacidad inhibitoria de amplio espectro mostrada por las cepas evaluadas podría servir como base para estudios posteriores de la interacción antagonista de las bacterias frente a posibles patógenos en el hospedero.

La metodología aplicada utilizando como cepa testigo a Staphylococcus aureus ATCC 663.3 fue clave en el aislamiento y selección inicial de un número considerable de cepas inhibitorias (83). L: l uso de esta bacteria (Gram positiva) como indicadora de antagonismo permitió recuperar mayor número de cepas marinas gracias a la alta sensibilidad inhibitoria mostrada en comparación con las bacterias Gram ncyativas (resultado no descrito). En este sentido, nuestros resultados son coincidentes con los Lrabajos de l. wmos et al. (1985); Nair y Simidu (1987) y Barja ct al. (1989) quienes a su vez utilizaron también bacterias Gram positivas como Bacillus subtilis, Stipliylucoccus sp. y Streptococcus.

E:I antagonismo ensayado entre cepas de bacterias marinas y cepas referenciales de patógenos marinos Gram negativos han sido considerados de interés en acuicultura por Dopazo et al. (1988), Lemos et al. (1985), Westerdahl et al. (1991) y Riquehne et al. (1996, 1997). Resultados similares son obtenidos en liss pruebas de antibiosi: critre bacteritu selcccionadas en el presente trabajo y la colucción de patógenos de peces y moluscos En consecuencia, la observación de una marcada efectividad inhibitoria sobre ictiopatógenos es evidentemente significativo tratándose además de cepas nativas aisladas de posibles hospederos de palógenos como es en este caso Argopecten purpuratus y Crassostrea giers.
Por otro lado los paligenos marinos Aeromonas sobria P-281. Vibrio anguillarum ATCC 19264 y V. anguillarum NCMB 2133 evidenciaron mayor sensibilidad en comparación con los patógenos Pseudomonas aeruginosa ATCC 15442 y Yersimia ruckeri PP-31. Datos similares fueron obtenidos también por Lemos et al. (1985b), Nair y Simidu, (1987) y Fabregas et al. (1991)

Trabajos previos (Gauthicr (1976), Barja et al. (1989) y Lemos et al. (1985) señalan que bajo condiciones de subcultivos prolongados muchas cepas ambientales pierden su capacidad antagúnica en Corma gradual. Ilegando inclusive a una pérdida total de actividad. En nuestro caso, si bien cs cierto que se noto una ligera disminución de esta actividad en algunas cepas, la gran mayoría conservó el potencial inhibitorio en cultivos mantenidos hasta por 90 días (no descrito en el presente trabajo). Esta particularidad es importante tomar en cuenta para casos de una posible aplicación práctica. Un aspecto particular de muchas bacterias ambientales es el comportamiento frecuentemente variable frentc a la tinción Gram ("Gram variable"). En nuestro caso, la mayoría de las cepas inhibitorias se observaron como Gram liegalivas durante la fase logaritmica pero como "Gram positivas" en cultivos tardíos. Esta característica para bacterias marinas es citada también por Gauthier (1975) e lmada et al. (1985).

A pesar cle que la pigmentación cle cepas no fue un criterio de selección en el presente trabajo, las cepas OS.16. OS.26 y CA. 13 fueron pigmontadas y presentaron fuerte actividad inhibitoria con todos los patógenos ensayados. Autores como Gauthier (1975), Gauthier y Flatau (1976), Lemos etal. (1985), Dopazo et al. (1988), entre otros, seleccionaron sus cepas considerando la pigmentación. obteniendo en la mayoría de los casos cepas fuertemente inhibitorias. A partir de estos resultados podríamos suponer que ciertas bacterias marinas pigmentadas representarian 
cepas con mayores potencialidades de producir sustancias inhibitorias de hacterias patógenas de organismos marinos.

El género predominante de las cepas inhibitorias fue Vibrio (40\%). Estc resultado no hace más que corroborar la microflora naiva que predomina en medios acuáticos asociados a organismos marinos. Sobre la base de estudios realizados por otros autores, los vibrios son comúnmente la fuente de sustancias inhibitorias y por tanto antagonistas a otras especies bacterianas del mismo hábitat sean o no patógenos de peces y moluscos (Buck y Meyers, 1965. Doggett, 1968. Olsson et al. 1992, I cón 1996, Riquelme et al. 1995, 1997). Cepas inhibitorias identificadas en el presente trabajo como Flavobaclerium (OS. 16 y OS.26) resultaron ser los mejorss antagonistas y merecen sin duda estudios complemenlarios, a diferencia de aquellas reportadas por Okami (1986), quien a su vez resalta en Flavobucfertum su actividad antiparasitaria.

Un aspecto de las bacterias marinas que ha sido tomada en cuenta muy escasamente es la capacidad de producir enzimas extracelulares. Al respecto, ()gana y Shimblal (1999) consideran esta caraciuristica de suma importancia sobre todo por las aplicaciones que éstas tendrian en biotecnología. Nuestros aislados, además del potencial inhibitorio, resultaron tener capacidad en la producción de exoenzimas que actúan frente a diversos polimeros.

Los resultados obtenidos en este trabajo representan un aporte a las investigaciones recientes sobre bacterias marinas producluras de sustancias inhibitorias y su posible aplicación en acuicultura intensiva. En este sentido, queda abierta la posibilidad de que las cepas seleccionadas sean evaluadas en el control de parógenos que afectan a cultivos inlensivos de invertebrados como de larvas de Argopecten purpuraus y Crassostrea gigas.

\section{REFERENCIAS BIBLIOGRÁFICAS}

Barja. J.: M. Lemos y A. Torarso. 1989. Puriticulion and characterization of an antibacterial substance produced by a marine Alteromonas species. Anlimicrobial. agent and chemoiliaphi. 33: 1673-1679.

Baumann. L.: M. Baumann: M. Mendely R. Allen. 1972 Taxonomy of acrobic marinc eshacteria. J. Bacteriol. 110: $402-129$.

Bonar. D: R. Meiner y R. Colwell. 1986. Microbial invertebrate interaction: and pointial lur biolechnology. Microb. Fcul. 12: 101-110.

Buck, f. y S. Meyers. 1965. Anti-yeast activity in marine environmenes: licological considerations. Limnol Occanographic 10:385-391.

Dogaretl. R. 1968. Veu mu-Pseudomonas agent isolated liom a marinc bisrio. J. Bacteriol 95: 1972 1973

Dopazo, C.: M. I.emos; C. Lodeiros; I. Bolinches: I. Barja y $\wedge$. Toranzo. 1988. Inhibitory activity of antibiotic proctucing marinc bacteria against lish pathouens. J. Appl Bacleriol. 65: 97-101

Douillet. P. y C. langdon 1994. Lise ol a probiotic for the culture of larvac of the Pacific Oyster. (Crassostreagiges Thumberg). Aquaculure 119: $25-40$.

Fabregas, J : A Muñoz; A. Otcro; J. Barjay M. Romaris 1991. A preliminary study on antimicrobial activities of some bacteria isolaced from marine environment. Nippon Suisan (iakkaishi. 57(7): 1377-1382.

Gaulyier. M. 1975. Morphological. physiological and bioch.mical charactoristic of some violespiemented bacleria isolated from scawater. Cin. I. Micrubiol. 22: 138-149.

Gauthier. M. 1976. Alleromonas rubra sp. Nov: a new marine antibiotic-producing backerium. Int. J. Syst. Bacteriol. 26: 459-466.

Gauthier. M. y G. I'Istau. 1976. Antibacterial activity of numbe violet - pigmented Alceromonas with special reference to the production of brominated compounds. ('in. I. Microbiol. 22: 1612-1619.

Imada, C.; U. Simidu y N. Taga. 1985. Isolation and characturizatium of marine bacteria producing alkaline, proteusa inhibitor. Bull, Ipn. Soc. Se fish. 51: 799-803.

Jcanthon, C: I). Pricur y J. Cochard. 1988 Bacterioloyical survey of antibiotic treated sea waters in a Pecton moximus. Hatchery. Aquacult...s. 71: $1-8$.

Jensen. P. y W. Finicial. 1995 . The relative abundance and seawater requirements of Gran positive bacteria in near-shore tropical marine samples. Microb. kul. 29:249-257. 
Karunasagar, I.; R. Pai y G. Malathi. 1994. Mass mortality of Pencueus monodon larvae due to antibiotic-resistent Vibrio harvey infection. Aquaculture. 119: 25-40

Lemos, M.: A. Toranzo y J. Barja. 1985b. Antibiotic activity of epiphytic bacteria isolated from intertidal sea-weeds. Microb. Ecol. 11: 149163.

León, J. 1996. Cepas nativas del Bacterioneuston marino con actividad antagónica frente a bacterias ictiopatógenas; caracterización preliminar de sustancias inhibitorias. Tesis de Grado de Magisicr en Ciencias Microbiológicas. Universidad Catulica de Valparaiso. Instituto de Biología. Facultad de Ciencias Basicas y Matematicas

Marly. P. y Y. Marlin. 1992. Acrobic heterotrophic bacteria associated with some Medilerranean coastal benthic invertebrates: Characterization of strains, exoenzyme and antibiolic production. Mar Life. 1(1): 1-8

$\because$ invarro, R.; L. Sturla; O. Cordcro y M. Avedaño. 1991. Fisheries and Aquaculture: Chile. Pp 10011015. In Scallops: Biology, Ecology and Aquaculture. Elsevier Scicnce Publisher, Amstcrdam.

air, S. y U. Simidu. 1987. Distribution and siguificance of heterotrophic marine bacteria wilh antibacterial activity. Appl. Environ. Microbiol. 53: 2957-2962

Ogawa, J. y S. Shimizu. 1999. Microbial enzymes new industrial applications from traditional screcning mcthods. Trends in Biotechnology. 17. 13-20

Okami, Y. 1986. Marine microorganism as a source of bioactive agents. Micrub. Ecol. 12: 67-68.

Oliver, J. 1982. Taxonomic scheme for the identification of marine bacteria. Deep-sea Res. 29.795-798.
Olsson, J.; A. Westerdahl; P. Cunway y S. Kjelleberg 1992. Intestinal colonization potentia! of lurbol (Scophthalmus maximus) and Dab (Liminda limanda). Asiociated bacteria with inhibitury cffecls against Vibrio angullarum Appl. Environ. Microbiol. 58(2): 551-556.

Ortigosa. M.: E. Garay y M. Pujalte. 1994. Numerical taxonomy of acrobic. Gram-negative bacteria associated with oysters and surrounding seawater of the mediterranean coast. System. Appl Microbiol. 17: 589-600.

Riquelme, C.; O. Hayashida; N. Vergara; A Vasquez: Y. Morales y P. Chave\% 1995. Bacteriology of the scallop Argopecten purpuralus (Lamarck, 1819) cullured in Chile. Aquaculture. 138: 49-60.

Riquelme, C.: G. Hayashida; R. Araya; A. Uchida: M. Salomi y Y. Ishida. 1996. Isolation of a native bacterial strain from the scallop Argopecten purpuratus with inhibitory effects against pathogenic Vibrios. I. Shelltish Research 15: 369-374

Riquelme, C.; R. Araya; N. Vergara; A. Rojas; H. Guaita y M. Candia. 1997. Potential probiotic strains in the culture of the chilean scallops Argopecten purpuralus (l.amarck 1819). Aquaculture 154: 17-26.

Sawabe, T.; Y. Oda; Y. Shiomi y Y. Ezura. 1995. Alginate degradation by bacteriat trom the gut of sea urchins and sbalones. Microb. Fcol. 30: 193-202.

Toranzo, A.; J. Barja y F. Hetrick. 1982. Antiviral activity of antibiotic-producing inarine bacteria. Can J. Microbiol. 28: 231-238

Westerdahl, A.; J. Olsson, J.: S. K.jellebers y P. Conway. 1991. Isolation and characterization of lisbot (Scophralmus maximus) as ocialed bactwid with inhibitory eflects against lihiris anguillarum. Appl. Environ. Microbiol. 57: 2223-28 